\title{
Glycaemic index, glycaemic load and ovarian cancer risk: a prospective cohort study
}

\author{
Stephanie AN Silvera ${ }^{1, *}$, Meera Jain ${ }^{2}$, Geoffrey R Howe ${ }^{3}$, Anthony B Miller ${ }^{2}$ \\ and Thomas E Rohan ${ }^{4}$ \\ 'Department of Health and Nutrition Science, Montclair State University, 1 Normal Avenue, University Hall, Room \\ 4171, Montclair, NJ 07043, USA: ${ }^{2}$ Department of Public Health Sciences, University of Toronto, Toronto, Canada: \\ ${ }^{3}$ Department of Epidemiology, Mailman School of Public Health, Columbia University, New York, NY, USA: \\ ${ }^{4}$ Department of Epidemiology and Population Health, Albert Einstein College of Medicine, Bronx, NY, USA
}

Submitted 5 December 2005: Accepted 8 December 2006: First published online 2 March 2007

\begin{abstract}
Background: There is some evidence that plasma insulin levels might influence ovarian cancer risk. Glyacemic index (GI) and glycaemic load (GL) are measures that allow the carbohydrate content of individual foods to be classified according to their postprandial glycaemic effects and hence their effects on circulating insulin levels. Therefore, we examined ovarian cancer risk in association with GI and GL, and intake of dietary carbohydrate and sugar.

Methods: The study was conducted in a prospective cohort of 49613 Canadian women enrolled in the National Breast Screening Study (NBSS) who completed a selfadministered food-frequency questionnaire (FFQ) between 1980 and 1985. Linkages to national mortality and cancer databases yielded data on deaths and cancer incidence, with follow-up ending between 1998 and 2000. Data from the FFQ were used to estimate overall GI and GL, and Cox proportional hazards models were used to estimate hazard ratios (HRs) and 95\% confidence intervals (CIs) for the association between energy-adjusted quartile levels of GL, overall GI, total carbohydrates, total sugar and ovarian cancer risk.

Results: During a mean 16.4 years of follow-up, we observed 264 incident ovarian cancer cases. GI and total carbohydrate and sugar intakes were not associated with ovarian cancer risk in the total cohort. GL was positively associated with a $72 \%$ increase in risk of ovarian cancer $\left(\mathrm{HR}=1.72,95 \% \mathrm{CI}=1.13-2.62, P_{\text {trend }}=0.01\right)$ and the magnitude of the association was slightly greater among postmenopausal $\left(\mathrm{HR}=1.89,95 \% \mathrm{CI}=0.98-3.65, P_{\text {trend }}=0.03\right)$ than among premenopausal women $\left(\mathrm{HR}=1.64,95 \% \mathrm{CI}=0.95-2.88, P_{\text {trend }}=0.07\right)$.

Conclusions: Our data suggest that consumption of diets with high GL values may be associated with increased risk of ovarian cancer.
\end{abstract}

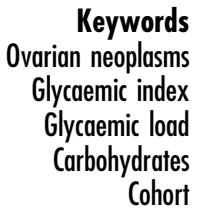

Ovarian cancer is the fourth most frequent cause of cancer death among women ${ }^{1}$, with 5 -year survival rates averaging between 25 and $30 \%{ }^{2}$. Increased ovarian synthesis of sex steroid hormones may contribute to the development of ovarian cancer ${ }^{3}$. Insulin has been shown to stimulate ovarian production of androgens ${ }^{4,5}$, which are direct precursors of oestrogen synthesis. Insulin has also been shown to downregulate synthesis of insulin-like growth factor-binding protein-1 (IGFBP-1), thereby increasing unbound levels of insulin-like growth factor-I (IGF-I) and hence IGF-I activity ${ }^{6-9}$. IGFs, which are produced in the ovaries and elsewhere in the body ${ }^{1}$, have been implicated in ovarian tumorigenesis ${ }^{10}$.

The glycaemic index (GI) is a means of classifying the carbohydrate content of individual foods according to their postprandial glycaemic effects and hence their effects on blood insulin levels ${ }^{11-13}$. Low-GI diets are associated with a relatively low postprandial rise in insulin ${ }^{14}$, and high-GI diets are associated with hyperinsulinaemia $^{11,15,16}$. Glycaemic load (GL) is a measure of the total glycaemic effect of the diet. It can be estimated using both GI values and the carbohydrate content of foods ${ }^{15}$, and therefore it reflects both the type and the amount of dietary carbohydrate consumed. Given the effects of highGI and high-GL diets on circulating insulin levels, it is conceivable that such diets might be associated with an increased risk of ovarian cancer via modulation of ovarian oestrogen synthesis ${ }^{3}$.

To date, it appears that the relationship between overall GI and GL and ovarian cancer risk has been examined in only one epidemiological study ${ }^{17}$. In that investigation, a case-control study in Italy, the authors found statistically 
significant positive associations between GI, GL, total carbohydrate intake and ovarian cancer risk ${ }^{17}$. Given the current lack of data regarding these relationships, we examined the relationship between overall GI and GL, as well as total carbohydrate and total sugar consumption (included because of their strong association with postprandial insulin response ${ }^{18,19}$ ), and ovarian cancer risk in a prospective cohort study of Canadian women.

\section{Materials and methods}

\section{Study population}

The design of the study has been described in detail elsewhere $^{20}$. Briefly, 89835 women aged 40-59 years were recruited into the Canadian National Breast Screening Study (NBSS) between 1980 and 1985 from the general Canadian population by various means, including personal invitation by letter, group mailings to employees of large institutions and to members of professional associations, advertisements in newspapers, and public service announcements on radio and television ${ }^{21}$. Women enrolled in the NBSS were randomised to either the screening arm or the control arm, and were followed-up to assess rates of referral for screening, rates of detection of breast cancer from screening and from community care, nodal status, tumour size and rates of death from all causes and from breast cancer ${ }^{22}$.

\section{Questionnaires}

At recruitment into the cohort, participants completed selfadministered questionnaires that sought information on demographic characteristics, lifestyle factors, menstrual and reproductive history, and use of oral contraceptives and replacement oestrogens. Women who reported having regular menstrual periods within the past 12 months were classified as premenopausal. Women whose menstrual periods ceased at least 12 months before enrolment into the study were considered to be post-menopausal $^{23}$.

Starting in 1982 (i.e. after some participants had completed their scheduled visits to the screening centres), a self-administered food-frequency questionnaire (FFQ) was distributed to all new attendees at all screening centres and to women returning to the screening centres for re-screening ${ }^{24}$. The FFQ sought information on usual portion size and frequency of consumption of 86 food items, and included photographs of various portion sizes to assist respondents with quantifying intake. A comparison between the self-administered questionnaire and a full interviewer-administered questionnaire, which has been subjected to both validity and reliability testing ${ }^{24}$ and used in a number of epidemiological studies ${ }^{25}$, revealed that the two methods gave estimates of intake of the major macronutrients and dietary fibre which strongly correlated with each other (correlation coefficients ranged from 0.47 for cholesterol to 0.72 for vegetable protein; for dietary fibre, the correlation coefficient was 0.70$)^{24}$. A total of 49613 dietary questionnaires were returned and available for analysis.

\section{Calculation of nutrient intake, overall glycaemic index and glycaemic load}

Data from the completed self-administered FFQs were used to estimate daily intake of nutrients using a database for Canadian foods that has been described elsewhere ${ }^{25}$. Data from the FFQ were also used to estimate overall GI and GL. GI values of foods were obtained from published reports based on studies in North America ${ }^{15}$. Total dietary GL was calculated by multiplying the carbohydrate content (in grams) of a standard serving size of a given food item by the number of servings of that food item consumed per day and by its GI value, and then summing the values for all food items reported. Overall GI, a variable that represents the relative proportion of high-GI foods in the diet ${ }^{26}$, was calculated by dividing the total dietary GL by the total carbohydrate content of the diet. When the reported GI values for foods were observed to vary across studies, we used the mean of the reported values of GI for that food. The main foods contributing to GL in the cohort are listed in a footnote to Table 1.

\section{Ascertainment of incident ovarian cancer cases and deatbs}

Incident ovarian cancer cases and deaths amongst cohort members were ascertained, respectively, by means of computerised record linkages to the Canadian Cancer Database and to the National Mortality Database, both of which are maintained by Statistics Canada. The linkages to the databases yielded data on cancer incidence and mortality to 31 December 2000 for women in Ontario, 31 December 1998 for women in Quebec, and 31 December 1999 for women in other provinces.

\section{Statistical analysis}

Of the 49613 women for whom dietary data were available, we excluded women with extreme energy intake values (at least three standard deviations above or below the mean value for $\log _{\mathrm{e}}$ caloric intake) $(n=502)$; women with prevalent ovarian cancer at baseline ( $n=20)$; and women who had undergone a bilateral oophorectomy prior to enrolment in the study $(n=315)$. These exclusions left 48776 women available for analysis, amongst whom there were 264 incident cases of ovarian cancer. Study participants were considered to be at risk from their date of enrolment until the date of diagnosis of ovarian cancer, the date of termination of follow-up (the date to which cancer incidence data were available for women in the corresponding province) or the date of death, whichever occurred earliest.

Cox proportional hazards models (using age as the time scale) were used to estimate hazard ratios (HRs) and 95\% confidence intervals (CIs) for ovarian cancer risk in 
Table 1 Age-adjusted baseline distributions of dietary, lifestyle and hormonal factors by quartiles of energy-adjusted glycaemic load $^{*}$

\begin{tabular}{|c|c|c|c|c|c|}
\hline & \multicolumn{5}{|c|}{$\begin{array}{l}\text { Quartiles of energy-adjusted } \\
\text { glycaemic load }\left(\mathrm{g} \mathrm{day}^{-1}\right)\end{array}$} \\
\hline & $<125$ & $125-147$ & $148-169$ & $>169$ & $P$-value \\
\hline Mean glycaemic load (g day ${ }^{-1}$ ) & $103.2(18.1) \dagger$ & $136.3(6.4)$ & $157.5(6.3)$ & $191.0(20.9)$ & $<0.0001$ \\
\hline Mean overall glycaemic index & $73.9(24.5)$ & $79.1(22.4)$ & $80.6(22.2)$ & $82.9(24.6)$ & $<0.0001$ \\
\hline Mean total carbohydrates $\left(\mathrm{g} \mathrm{day}^{-1}\right)$ & $153.0(52.1)$ & $185.5(51.7)$ & $209.6(56.2)$ & $250.2(80.8)$ & $<0.0001$ \\
\hline Mean total sugar $\left(\mathrm{g} \mathrm{day}^{-1}\right)$ & $61.6(19.5)$ & $77.3(19.2)$ & $85.4(20.4)$ & $99.6(29.7)$ & $<0.0001$ \\
\hline Mean total fibre $\left(\mathrm{g}_{\text {day }}{ }^{-1}\right)$ & $17.3(6.2)$ & $20.0(6.1)$ & $21.4(6.4)$ & $22.9(7.7)$ & $<0.0001$ \\
\hline Mean energy intake (kcal day ${ }^{-1}$ ) & $2075(743)$ & $2020(587)$ & $2058(577)$ & $2133(653)$ & $<0.0001$ \\
\hline Mean age (years) & $48.1(5.5)$ & $48.5(5.6)$ & $48.7(5.7)$ & $48.9(5.7)$ & $<0.0001$ \\
\hline Mean body mass index $\left(\mathrm{kg} \mathrm{m}^{-2}\right)$ & $25.1(4.4)$ & $25.0(5.0)$ & $24.7(4.3)$ & $24.4(4.5)$ & $<0.0001$ \\
\hline Ever smoker (\%) & 59.9 & 50.2 & 44.4 & 39.7 & $<0.0001$ \\
\hline Any alcohol intake (\%) & 80.3 & 78.4 & 73.6 & 63.4 & $<0.0001$ \\
\hline Any vigorous physical activity (\%) & 56.2 & 59.4 & 59.8 & 56.6 & 0.46 \\
\hline Age at menarche $\leq 12$ years $(\%)$ & 42.6 & 42.1 & 40.4 & 37.8 & $<0.0001$ \\
\hline Ever use of oral contraceptive (\%) & 63.6 & 61.5 & 58.6 & 53.9 & $<0.0001$ \\
\hline Postmenopausal at baseline (\%) & 39.1 & 42.3 & 43.6 & 46.4 & $<0.0001$ \\
\hline Ever use of hormone replacement therapy (\%)‡ & 49.7 & 48.7 & 47.9 & 46.5 & 0.002 \\
\hline Parous (\%) & 84.6 & 86.0 & 85.6 & 84.3 & 0.001 \\
\hline Age at first birth§ & $23.8(4.7)$ & $24.2(4.7)$ & $24.5(4.7)$ & $24.6(4.8)$ & $<0.0001$ \\
\hline
\end{tabular}

* The main foods contributing to glycaemic load in the cohort include white bread (sliced), rolls, muffins, potatoes (baked, boiled and mashed), French fries, cakes, cookies, rice, pasta, pizza, cold breakfast cereals, pies and tarts, cola, other soft drinks, citrus fruits and juices and other fruits, crisp snacks (such as potato chips or popcorn), candy, chocolate, peas, beans and lentils, hot breakfast cereals, dark and wholegrain breads, corn, root vegetables other than potatoes, jam, jelly and honey, sugar in tea or coffee, ice cream and peanut butter.

$\dagger$ Numbers in parentheses represent the standard deviation.

$\ddagger$ Among postmenopausal women only.

$\S$ Among parous women only.

association with energy-adjusted quartile levels of GL, overall GI, and total carbohydrate and total sugar intake; energy adjustment was performed using the residual method $^{27}$. Multivariate models included the variables listed in the footnote of Table 2. To test for trend, we fitted the median value of each quartile level as an ordinal variable in the risk models, and evaluated the statistical significance of the coefficient using the Wald test ${ }^{28}$. We examined the associations overall and within strata defined by menopausal status. Stratified multivariate models included the variables listed in a footnote in Table 3. Tests for interaction were based on likelihood ratio tests comparing models with and without product terms representing the variables of interest. Use of the lifetest procedure in SAS ${ }^{\circledR}$ showed that the proportional hazards assumption was met in this data set. All analyses were performed using SAS version 9 (SAS Institute). All statistical tests were two-sided, and $P$-values $<0.05$ were considered to be statistically significant.

\section{Results}

The average duration of follow-up for cohort members was 16.4 years, corresponding to a total of 801414 personyears of follow-up for the cohort. The mean $( \pm$ standard deviation (SD)) age at diagnosis for the cases was 59.4 $( \pm 7.2)$ years. For the cohort as a whole, the means $( \pm S D)$ of the energy-adjusted overall GI and GL were 79.1 $( \pm 23.7)$ and $147.0( \pm 35.1) \mathrm{g} \mathrm{day}^{-1}$, respectively. There was an approximately 2-fold variation in mean GL values between the lowest and highest quartile levels (Table 1).

Compared with those with relatively low GL values, women with high GL values were less likely to have consumed alcohol, to have ever smoked, to have had a relatively early age at menarche and to have ever used oral contraceptives and hormone replacement therapy, but they were more likely to be postmenopausal at baseline, and they consumed more total carbohydrates, sugar and fibre (Table 1). No appreciable variation was observed in mean energy intake, age at baseline, body mass index, participation in vigorous physical activity, parity or age at first birth by quartile levels of GL. The patterns for overall GI were similar to those for the GL (data not shown).

Table 2 shows that in age- and energy-adjusted models there was no association between GL, overall GI, total carbohydrate or total sugar intake and risk of ovarian cancer. After multivariate adjustment, the HRs for total carbohydrate and total sugar remained essentially unchanged, while there was some suggestion of a weak positive association with overall GI, although this association was not statistically significant. In contrast, after multivariate adjustment, GL was positively associated with a $72 \%$ increase in risk of ovarian cancer (HR for highest vs. lowest quartile level $=1.72,95 \% \mathrm{CI}=1.13-$ 2.62, $P_{\text {trend }}=0.01$ ). Mutual adjustment for GI, GL, carbohydrate and sugar intake in the model did not materially alter these associations. After additional adjustment for dietary carbohydrate, the association between overall GI and ovarian cancer risk was not altered 
Table 2 Adjusted ${ }^{*}$ hazard ratios and $95 \%$ confidence intervals for the association between overall glycaemic index, glycaemic load, total carbohydrate intake, total sugar intake and risk of ovarian cancer

\begin{tabular}{|c|c|c|c|}
\hline & \multirow[b]{2}{*}{ Cases/person-years } & \multicolumn{2}{|c|}{$\begin{array}{c}\text { Hazard ratio } \\
\text { confidence interval }(95 \% \mathrm{Cl})\end{array}$} \\
\hline & & $\begin{array}{l}\text { Age and energy } \\
\text { adjusted }\end{array}$ & $\begin{array}{l}\text { Multivariate } \\
\text { adjusted }^{*}\end{array}$ \\
\hline \multicolumn{4}{|c|}{ Glycaemic load ( $\left.\mathrm{g} \mathrm{day}^{-1}\right)$} \\
\hline$<125$ & $53 / 201225$ & 1.00 (referent) & 1.00 (referent) \\
\hline $125-147$ & $68 / 200534$ & $1.30(0.91-1.88)$ & $1.45(0.96-2.19)$ \\
\hline $148-169$ & $75 / 200269$ & $1.44(1.00-2.06)$ & $1.93(1.29-2.88)$ \\
\hline$>169$ & 68/199 385 & $1.33(0.93-1.92)$ & $1.72(1.13-2.62)$ \\
\hline$P$ for trend & & 0.10 & 0.004 \\
\hline \multicolumn{4}{|c|}{ Overall glycaemic index } \\
\hline$<63$ & $70 / 200001$ & 1.00 (referent) & 1.00 (referent) \\
\hline $64-76$ & $65 / 200653$ & $0.95(0.67-1.33)$ & $1.26(0.81-1.98)$ \\
\hline $77-92$ & $71 / 200118$ & $1.03(0.74-1.44)$ & $1.29(0.75-2.21)$ \\
\hline$>92$ & $58 / 200641$ & $0.82(0.58-1.17)$ & $1.27(0.65-2.47)$ \\
\hline$P$ for trend & & 0.37 & 0.66 \\
\hline \multicolumn{4}{|c|}{ Total carbohydrate $\left(\mathrm{g} \mathrm{day}^{-1}\right)$} \\
\hline$<152$ & $59 / 201124$ & 1.00 (referent) & 1.00 (referent) \\
\hline $152-191$ & $78 / 200523$ & $1.31(0.93-1.84)$ & $1.33(0.89-1.98)$ \\
\hline $192-236$ & $52 / 200544$ & $0.85(0.58-1.24)$ & $0.96(0.60-1.54)$ \\
\hline$>236$ & 75/199 223 & $1.30(0.92-1.84)$ & $1.33(0.75-2.35)$ \\
\hline$P$ for trend & & 0.37 & 0.42 \\
\hline \multicolumn{4}{|c|}{ Total sugar ( $\left.\mathrm{g} \mathrm{day}^{-1}\right)$} \\
\hline$<64$ & $60 / 200227$ & 1.00 (referent) & 1.00 (referent) \\
\hline $64-79$ & $63 / 200662$ & $1.06(0.74-1.51)$ & $1.13(0.76-1.69)$ \\
\hline $80-95$ & $80 / 200385$ & $1.31(0.93-1.84)$ & $1.68(1.14-2.47)$ \\
\hline$>95$ & $61 / 200,139$ & $0.98(0.87-1.41)$ & $1.17(0.76-1.79)$ \\
\hline$P$ for trend & & 0.85 & 0.21 \\
\hline
\end{tabular}

* Multivariable models included age (time to event variable), body mass index in $\mathrm{kg} \mathrm{m}^{-2}(<25,25-29, \geq 30$ ), alcohol (any vs. none), use of hormone replacement therapy (ever vs. never), use of oral contraceptives (ever vs. never), parity (parous vs. nulliparous), age at menarche ( $\leq 12$ vs. $>12$ years of age), menopausal status at baseline, total energy intake (as a continuous variable), participation in vigorous physical activity (any vs. none), energy-adjusted total fibre intake (quartiles), study centre and treatment allocation (intervention vs. control).

substantially (HR highest vs. lowest quartile $=1.25$, 95\% $\mathrm{CI}=0.64-2.45)$, but the positive association between GL and ovarian cancer risk was somewhat stronger (HR highest vs. lowest quartile $=2.15$, 95\% CI $=1.29-3.60$; data not shown).

While GL was positively associated with risk of ovarian cancer in both premenopausal and postmenopausal women (Table 3), the risk for the highest relative to the lowest quartile level appeared to be slightly greater among postmenopausal $\quad(\mathrm{HR}=1.89, \quad 95 \% \quad \mathrm{CI}=0.98-3.35$, $\left.P_{\text {trend }}=0.03\right)$ than among premenopausal women $\left(\mathrm{HR}=1.65,95 \% \mathrm{CI}=0.95-2.88, P_{\text {trend }}=0.07\right)$. However, on formal testing, the interaction between GL and menopausal status was not statistically significant $\left(\chi^{2}(3)=2.18, P=0.54\right)$. Similarly, although the HR for ovarian cancer risk associated with a relatively high overall GI was above unity among postmenopausal ( $\mathrm{HR}=1.88$, $\left.95 \% \mathrm{CI}=0.71-5.00, \quad P_{\text {trend }}=0.44\right)$ but not premenopausal women $(\mathrm{HR}=0.92, \quad 95 \% \quad \mathrm{CI}=0.37-2.29$, $\left.P_{\text {trend }}=0.95\right)$, the interaction between GI and menopausal status was not statistically significant $\left(\chi^{2}(3)=4.37\right.$, $P=0.22)$. There was no association between total carbohydrate intake and ovarian cancer risk among pre- or postmenopausal women $\left(P_{\text {trend }}=0.70\right.$ and $P_{\text {trend }}=0.86$, respectively), whereas for total sugar consumption there was no association with risk among premenopausal women but some suggestion of a positive association among postmenopausal women $\left(P_{\text {trend }}=0.84\right.$ and $P_{\text {trend }}=0.08$, respectively).

No heterogeneity of results was found upon stratification by smoking history (ever vs. never), age at menarche, use of hormone replacement therapy or alcohol consumption. There was some evidence of heterogeneity by parity (parous vs. non-parous) for GI $\left(\chi^{2}(3)=10.62\right.$, $P=0.01)$, but not GL $\left(\chi^{2}(3)=2.27, P=0.52\right)$, carbohydrate intake $\left(\chi^{2}(3)=6.07, P=0.11\right)$ or sugar consumption $\left(\chi^{2}(3)=2.68, P=0.44\right)$.

The results for each of the analyses presented above were similar after exclusion of case subjects diagnosed within 1 year of recruitment $(n=10)$.

\section{Discussion}

In the prospective study reported here, we found a strong positive association between GL and ovarian cancer risk over a 16-year follow-up period. In contrast, there was no association between overall GI, total carbohydrate or total sugar intake, and risk over a 16-year follow-up period in the total study population. Although the association with GL was slightly stronger in women who were postmenopausal at baseline than in those who were premenopausal, there was no statistical evidence of effect modification by baseline menopausal status. Indeed, given that $88 \%$ of ovarian cancer cases in our study population were diagnosed at or above 51 years of age, the average age at menopause in North America ${ }^{31}$, it is evident that our results are largely representative of ovarian cancers diagnosed postmenopausally. Our finding of an association with GL but not GI may reflect the fact that the proportion of high-GI foods in the diet may not be as good an indicator of physiological response as GL, which also takes into account the quantity of intake of rapidly absorbed carbohydrates ${ }^{26}$.

Only one previous study has examined the association between GI, GL and ovarian cancer risk. In that investigation, a case-control study in Italy, Augustin et al. $^{17}$ analysed data on 1031 incident cases and 2411 controls, and found a statistically significant increase in ovarian cancer risk among women in the highest vs. the lowest quartile levels for GL and GI. Similar to our findings, upon stratification by menopausal status, GI and GL were associated more strongly with ovarian cancer risk among postmenopausal women ${ }^{17}$.

Three case-control studies ${ }^{17,29,30}$ and one prospective study $^{31}$ have examined the association between total carbohydrate intake and ovarian cancer risk. Of these, two studies found a statistically significant positive association between total carbohydrate intake and risk $^{17,30}$ and one 
Table 3 Adjusted* hazard ratios and $95 \%$ confidence intervals for the association between overall glycaemic index, glycaemic load, total carbohydrate intake, total sugar intake and risk of ovarian cancer, stratified by menopausal status

\begin{tabular}{|c|c|c|c|}
\hline & \multicolumn{3}{|c|}{ Hazard ratio (95\% confidence interval) } \\
\hline & Premenopausal & Postmenopausal & $P$ for interaction \\
\hline \multicolumn{4}{|l|}{$\begin{array}{l}\text { No. of cases/person-years } \\
\left.\text { Glycaemic load (a day }{ }^{-1}\right) \dagger\end{array}$} \\
\hline$<125$ & 1.00 (referent) & 1.00 (referent) & \\
\hline $125-147$ & $1.38(0.81-2.35)$ & $1.58(0.81-3.06)$ & \\
\hline $148-169$ & $1.54(0.90-2.64)$ & $2.59(1.39-4.84)$ & \\
\hline$>169$ & $1.65(0.95-2.88)$ & $1.89(0.98-3.65)$ & \\
\hline$P$ for trend & 0.07 & 0.03 & 0.54 \\
\hline \multicolumn{4}{|l|}{ Overall glycaemic index $\dagger$} \\
\hline$<63$ & 1.00 (referent) & 1.00 (referent) & \\
\hline $64-76$ & $1.00(0.53-1.83)$ & $1.67(0.86-3.25)$ & \\
\hline $77-92$ & $1.30(0.64-2.66)$ & $1.25(0.55-2.87)$ & \\
\hline$>92$ & $0.92(0.37-2.29)$ & $1.88(0.71-5.00)$ & \\
\hline$P$ for trend & 0.95 & 0.44 & 0.22 \\
\hline \multicolumn{4}{|l|}{ Total carbohydrate $\left(\mathrm{g}_{\text {day }}{ }^{-1}\right)$} \\
\hline$<152$ & 1.00 (referent) & 1.00 (referent) & \\
\hline $152-191$ & $1.29(0.75-2.20)$ & $1.35(0.74-2.47)$ & \\
\hline $92-236$ & $0.93(0.48-1.77)$ & $0.98(0.49-1.99)$ & \\
\hline$>236$ & $1.40(0.64-3.06)$ & $1.26(0.54-2.93)$ & \\
\hline$P$ for trend & 0.70 & 0.86 & 1.00 \\
\hline \multicolumn{4}{|l|}{ Total sugar $\left(\mathrm{g}_{\text {day }}{ }^{-1}\right)$} \\
\hline$<64$ & 1.00 (referent) & 1.00 (referent) & \\
\hline $64-79$ & $0.89(0.53-1.49)$ & $1.67(0.87-3.21)$ & \\
\hline $80-95$ & $1.38(0.84-2.26)$ & $2.35(1.24-4.44)$ & \\
\hline$>95$ & $0.87(0.49-1.56)$ & $1.79(0.91-3.50)$ & \\
\hline$P$ for trend & 0.84 & 0.08 & 0.31 \\
\hline
\end{tabular}

* Multivariable models included age (time to event variable), body mass index in $\mathrm{kg} \mathrm{m}^{-2}(<25,25-29$, $\geq 30$ ), alcohol (any vs. none), use of hormone replacement therapy (ever vs. never), use of oral contraceptives (ever vs. never), parity (parous vs. nulliparous), age at menarche ( $\leq 12$ vs. $>12$ years of age), menopausal status at baseline, total energy intake (as a continuous variable), participation in vigorous physical activity (any vs. none), energy-adjusted total fibre intake (quartiles), study centre and treatment allocation (intervention vs. control).

†The total number of cases does not equal 264 because women classified as perimenopausal were not included in these analyses.

found no association ${ }^{29}$. In addition, Kushi et al. ${ }^{31}$ analysed data from the Iowa Women's Health Study (139 incident cases) and, in contrast to our findings, observed an $83 \%$ increase in ovarian cancer risk associated with the highest vs. the lowest quartile level of total carbohydrate intake (relative risk $=1.83,95 \% \mathrm{CI}=1.07-3.13$ ).

To date, only two case-control studies have examined the association between total dietary sugar intake and ovarian cancer risk, of which one ${ }^{32}$ found no association, while the other ${ }^{33}$ found a positive association. We are unaware of any previous cohort studies that have examined total sugar intake in association with ovarian cancer risk.

Our data are limited by the possibility of error with respect to the measurement of diet and the calculation of GL. Error in the measurement of daily intake of carbohydrates and sugars may have resulted from inaccurate recall ${ }^{34}$. Furthermore, measurement error might have occurred due to the fact that the GI values of some foods are currently based on only one or two, often small, studies ${ }^{15}$. In addition, no biological specimens were collected and we were therefore unable to test for the presence of relevant biomarkers such as IGF. Finally, although we adjusted our estimates for a wide range of potentially confounding variables, uncontrolled confounding by dietary and other factors cannot be excluded.

In conclusion, the results of our study suggest that dietary GL is associated with an increase in the risk of ovarian cancer. Our findings add to the growing body of knowledge concerning the potentially deleterious effects of high-GL diets ${ }^{35-37}$.

\section{Acknowledgements}

Sources of funding: This study was funded in part by the National Cancer Institute of Canada.

Conflict of interest declaration: There are no conflicts of interest to report.

Authorship responsibilities: M.J., G.R.H., A.B.M. and T.E.R. were involved with the administration of the initial intervention and data collection. S.A.N.S. was responsible for analysing the data and preparing the manuscript for submission.

Acknowledgements: We thank Statistics Canada, the provincial and territorial Registrars of Vital Statistics, and the Cancer Registry directors for their assistance in making the cancer incidence and mortality data available. 


\section{References}

1 Risch HA. Hormonal etiology of epithelial ovarian cancer, with a hypothesis concerning the role of androgens and progesterone. Journal of the National Cancer Institute 1998; 90: $1774-86$.

2 Gertig D, Hunter DJ. Ovarian cancer. In: Adami HO, Hunter DJ, Trichopoulos D, eds. Textbook of Cancer Epidemiology. Oxford: Oxford University Press, 2002; 378-99.

3 Lukanova A, Kaaks R. Endogenous hormones and ovarian cancer: epidemiology and current hypotheses. Cancer Epidemiology Biomarkers \& Prevention 2005; 14: 98-107.

4 Poretsky L, Kalin MF. The gonadotropic function of insulin. Endocrine Reviews 1987; 8: 132-41.

5 Nestler JE, Jakubowicz DJ. Decreases in ovarian cytochrome P450c17-alpha activity and serum free testosterone after reduction of insulin secretion in polycystic ovary syndrome. New England Journal of Medicine 1996; 335: 617-23.

6 Lukanova A, Lundin E, Micheli A, Akhmedkhanov A, Rinaldi S, Muti P, et al. Risk of ovarian cancer in relation to prediagnostic levels of C-peptide, insulin-like growth factor binding proteins-1 and -2 (USA, Sweden, Italy). Cancer Causes \& Control 2003; 14: 285-92.

7 Dal Maso L, Augustin LS, Franceschi S, Talamini R, Polesel J, Kendal CW, et al. Association between components of the insulin-like growth factor system and epithelial ovarian cancer risk. Oncology 2004; 67: 225-30.

8 Flyvbjerg A, Mogensen O, Mogensen B, Nielsen OS. Elevated serum insulin-like growth factor-binding protein 2 (IGFBP-2) and decreased IGFBP-3 in epithelial ovarian cancer: correlation with cancer antigen 125 and tumorassociated trypsin inhibitor. Journal of Clinical Endocrinology 1997; 82: 2308-13.

9 Lukanova A, Lundin E, Toniolo P, Micheli A, Akhmedkhanov A, Rinaldi S, et al. Circulating levels of insulin-like growth factor-1 and risk of ovarian cancer. International Journal of Cancer 2002; 101: 549-54.

10 Lee EJ, Mircean C, Shmulevich I, Wang H, Liu J, Niemisto A, et al. Insulin-like growth factor binding protein 2 promotes ovarian cancer cell invasion. Molecular Cancer 2005; 4: 7.

11 Holt S, Miller JC, Petocz P. An insulin index of foods: the insulin demand generated by $1000-\mathrm{kJ}$ portions of common foods. American Journal of Clinical Nutrition 1997; 66 : 1264-6.

12 Ionescu-Tirgoviste C, Popa E, Sintu E, Mihalache N, Cheta D, Mincu I. Blood glucose and plasma insulin responses to various carbohydrates in type 2 (non-insulin-dependent diabetes). Diabetologia 1983; 24: 80-4.

13 Jenkins DJ, Kendal CW, Augustin LS, Franceschi S, Hamidi M, Marchie A, et al. Glycemic index: overview of implications in health and disease. American Journal of Clinical Nutrition 2002; 76: 266S-73S.

14 Ludwig DS. Dietary glycemic index and obesity. Journal of Nutrition 2000; 130: 280S-3S.

15 Foster-Powell K, Holt SH, Brand-Miller JC. International table of glycemic index and glycemic load values. American Journal of Clinical Nutrition 2002; 76: 5-56.

16 Byrnes SE, Miller JCB, Denyer GS. Amylopectin starch promotes the development of insulin resistance in rats. Journal of Nutrition 1995; 125: 1430-7.

17 Augustin LS, Polesel J, Bosetti C, Kendall CWC, La Vecchia C, Parpinel M, et al. Dietary glycemic index, glycemic load and ovarian cancer risk: a case-control study in Italy. Annals of Oncology 2003; 14: 78-84.

18 Trout D, Behall KM. Prediction of glycemic index among high-sugar, low-starch foods. International Journal of Food Sciences and Nutrition 1999; 50: 135-44.
19 Wolever TMS, Brand-Miller JC. Sugars and blood glucose control. American Journal of Clinical Nutrition 1995; 62: 212S-27S.

20 Terry PD, Miller AB, Jones JG, Rohan TE. Cigarette smoking and the risk of invasive epithelial ovarian cancer in a prospective cohort study. European Journal of Cancer 2003; 39: 1157-64

21 Miller AB, Baines CJ, To T, Wall C. Canadian National Breast Screening Study. 1. Breast cancer detection and death rates among women aged 40-49 years. Canadian Medical Association Journal 1992; 147: 1459-76.

22 Miller AB, Baines CJ, To T, Wall C. Canadian National Breast Screening Study. 2. Breast cancer detection and death rates among women aged 50-59 years. Canadian Medical Association Journal 1992; 147: 1477-88.

23 Rohan TE, Hartwick W, Miller AB, Kandel RA. Immunohistochemical detection of c-erbB-2 and p-53 in benign breast disease and breast cancer risk. Journal of the National Cancer Institute 1998; 90: 1262-9.

24 Jain M, Harrison L, Howe GR, Miller AB. Evaluation of a self-administered dietary questionnaire for use in a cohort study. American Journal of Clinical Nutrition 1982; 36 : 931-5.

25 Morgan $\mathrm{AB}$, Jain $\mathrm{M}$, Miller $\mathrm{AB}$, Choi NW, Matthews $\mathrm{V}$, Munan L, et al. A comparison of dietary methods in epidemiologic studies. American Journal of Epidemiology 1978; 107: 488-98.

26 Lajous M, Willett W, Lazcano-Ponce E, Sanchez-Zamorano LM, Hernandez-Avila M, Romieu I. Glycemic load, glycemic index, and the risk of breast cancer among Mexican women. Cancer Causes \& Control 2005; 16: 1165-9.

27 Willett WC, Stampfer MJ. Total energy intake: implications for epidemiologic analyses. American Journal of Epidemiology 1986; 124: 17-27.

28 Rothman KJ, Greenland S. Modern Epidemiology. Philadelphia, PA: Lippincott-Raven, 1998.

29 McCann SE, Freudenheim JL, Marshall J, Graham S. Risk of human ovarian cancer is related to dietary intake of selected nutrients, phytochemicals and food groups. Journal of Nutrition 2003; 133: 1937-42.

30 Salazar-Martinez E, Lazcano-Ponce EC, Gonzalez Lira-Lira G, Escuerdo-De los Rios P, Hernandez-Avila M. Nutritional determinants of epithelial ovarian cancer risk: a casecontrol study in Mexico. Oncology 2002; 63: 151-7.

31 Kushi LH, Mink PJ, Folsom AR, Anderson KE, Zheng W, Lazovich D, et al. Prospective study of diet and ovarian cancer. American Journal of Epidemiology 1999; 149: 21-31.

32 Bidoli E, La Vecchia C, Montella M, Dal Maso L, Conti E, Negri E, et al. Nutrient intake and ovarian cancer: an Italian case-control study. Cancer Causes \& Control 2002; 13: 255-61.

33 Bosetti C, Negri E, Franceschi S, Pelucchi C, Talamini R, Montella M, et al. Diet and ovarian cancer risk: a casecontrol study in Italy. International Journal of Cancer 2001; 93: 911-5.

34 Willett WC, Stampfer MJ. Nutritional Epidemiology. New York: Oxford Univeristy Press, 1998.

35 Dickinson S, Brand-Miller JC. Glycemic index, postprandial glycemia and cardiovascular disease. Current Opinion in Lipidology 2005; 16: 69-75.

36 Colombani PC. Glycemic index and load - dynamic dietary guidelines in the context of diseases. Physiology \& Behavior 2004; 83: 603-10.

37 Brand-Miller JC. Glycemic load and chronic disease. Nutrition Reviews 2003; 61: S49-55. 